we believe that our results present strong evidence that breastfeeding provides protection against $\mathrm{RS}$ virus infection. This virus has been identified as a major factor in postneonatal morbidity and mortality. These observations can be added to the growing list of benefits for breast-feeding. There is general and official agreement that breast feeding should be encouraged more widely, ${ }^{17}$ but evidence of the kind we have presented, which suggests an advantage readily understood by the general public, should help to strengthen the case for this policy.

We thank Professor F E Hytten for help with the arrangements for collecting samples of colostrum and $\mathrm{Mr}$ Paul Clark for statistical help. We acknowledge the continuing support of the Medical Research Council.

\section{References}

${ }^{1}$ Newman, G, Infant Mortality. London, Methuen, 1906.
${ }^{2}$ Grulee, C G, Sanford, H N, and Herron, P H, Fournal of the American Medical Association, 1934, 103, 735.

${ }^{3}$ Robinson, M, Lancet, 1951, 1, 788.

4 Goldman, A S, and Smith, C W, Fournal of Paediatrics, 1973, 82, 1082.

${ }^{5}$ Downham, M A P S, et al, British Medical fournal, 1975, 1, 235.

6 Scott, R, and Gardner, P S, Fournal of Hygiene, 1970, 68, 581.

7 Scott, R, et al, Clinical and Experimental Immunology, in press.

${ }^{8}$ Barron, S L, Newcastle Maternity Survey, personal communication.

9 Hambling, M H, Fournal of Pathology and Bacteriology, 1966, 91, 625.

10 Glezen, W P, and Denny, F W, New England fournal of Medicine, 1973, 288, 498 .

11 Neligan, G A, et al, in preparation.

12 Medical Officer of Health's Report for Newcastle upon Tyne, p 41. 1972.

${ }^{13}$ Schmidt, E, Zeitschrift fur Kinderheilkunde, 1960, 84, 339.

${ }^{14}$ De Carlo, J, Tramer, A, and Startzman, H, American fournal of Diseases of Childhood, 1952, 84, 442.

${ }^{15}$ Frank, M M, and Gatewood, O M, American fournal of Diseases of Childhood, 1966, 111, 178.

16 Gardner, P S, McQuillin, J, and Court, S D M, British Medical fournal, $1970,1,327$.

17 Department of Health and Social Services, Present Day Practice in Infant Feeding, p 24. London, HMSO, 1974.

\title{
Lymphocyte cytotoxicity for kidney cells in renal tubular acidosis of autoimmune liver disease
}

\author{
A M G COCHRANE, D C TSANTOULOS, A MOUSSOUROS, I G McFARLANE, \\ A L W F EDDLESTON, ROGER WILLIAMS
}

British Medical fournal, 1976, 2, 276-278

\begin{abstract}
Summary
Sensitisation to a renal tubular antigen, Tamm-Horsfall glycoprotein, has been shown to be common in patients with renal tubular acidosis complicating autoimmune liver disease, and it has been suggested that this immune reaction, by damaging renal tubular cells, might be responsible for the acidification defect. The lymphocytes from 10 out of 13 patients with chronic active hepatitis or primary biliary cirrhosis and an associated renal tubular acidosis were shown to be cytotoxic for a kidney cell line known to secrete Tamm-Horsfall glycoprotein. The cytotoxic reaction was blocked by this antigen, but not by two other proteins, indicating that sensitisation to the renal glycoprotein was the likely cause of the target cell damage. Significant reduction in cytotoxicity after the addition of aggregated IgG suggested that the reaction was of the antibody-dependent cell-mediated type. These results, together with the finding of antigenic material in the surface membrane of liver cells that cross reacts immunologically with Tamm-Horsfall glycoprotein, provide an explanation for the association between chronic liver disease and renal tubular dysfunction.
\end{abstract}

Liver unit, King's College Hospital and Medical School, London SE5 9RS

A M G COCHRANE, MB, MRCP, senior registrar

D C TSANTOULOS, MD, research fellow

A MOUSSOUROS, MD, research fellow

I G MCFARLANE, BSC, PHD, senior research biochemist

A L W F EDDLESTON, DM, MRCP, lecturer and honorary consultant physician

ROGER WILLIAMS, MD, FRCP, consultant physician and director of unit

\section{Introduction}

On systematic investigation of patients with primary biliary cirrhosis or chronic active hepatitis there is often evidence of disease in other organs and this, like the liver damage, has been attributed to an autoimmune reaction. ${ }^{1}$ One of the commonest associations is with renal tubular acidosis, which in one study was found in an incomplete form in $32 \%$ of 228 cases. ${ }^{1}$ Using the leucocyte migration test and a kidney homogenate as antigen, Smith et $a l^{2}$ found sensitisation in $59 \%$ of patients with renal tubular acidosis. More recently we have shown sensitisation to a specific antigen present in this homogenate, the Tamm-Horsfall glycoprotein, in $91 \%$ of such patients. ${ }^{3}$ This antigen is secreted in the distal part of the nephron at the principal site of urinary acidification, ${ }^{4}$ and we suggested that the acidification defect in renal tubular acidosis might be due to immunologically mediated damage to the renal tubular cells in this region. To test this hypothesis we have investigated the cytotoxicity of lymphocytes from such patients for a cell line, derived from baby hamster kidney, which is known to produce a glycoprotein immunologically similar to the Tamm-Horsfall glycoprotein. ${ }^{5}$ We also studied the relation of this cytotoxic reaction to that directed against hepatocytes in patients with chronic active hepatitis. ${ }^{6}$

\section{Patients and methods}

Twenty patients with chronic active hepatitis and five with primary biliary cirrhosis were investigated, the diagnosis having been confirmed histologically in all cases. Apart from two of the newly diagnosed patients all the others with chronic active hepatitis were receiving either prednisone $15 \mathrm{mg}$ or prednisone $10 \mathrm{mg}$ plus azathioprine $75 \mathrm{mg}$ at the time of investigation. The five patients with primary biliary cirrhosis were taking part in an international double-blind trial of azathioprine versus placebo. None of the patients had metabolic acidosis, but in 10 of those with chronic active hepatitis and three with primary biliary cirrhosis the incomplete type of renal tubular acidosis was shown to be present, using an acid load test. After a single oral load of $37.5 \mathrm{mmol}(75 \mathrm{mEq})$ of calcium chloride urine was collected 
hourly for the next five hours; in normal subjects the urine $\mathrm{pH}$ is reduced to below $5 \cdot 2$ within this time."

\section{PREPARATION OF LYMPHOCYTES AND CYTOTOXICITY ASSAY}

Leucocyte-rich plasma obtained from $20 \mathrm{ml}$ of venous blood by dextran sedimentation was filtered through a cotton wool column ${ }^{7}$ to remove macrophages and polymorphs. The resulting cells were centrifuged over a Ficoll-Triosil density gradient ${ }^{*}$ to remove remaining neutrophils and red blood cells.

Baby hamster kidney cells (21/13 substrain $2 \mathrm{P}$ ) were maintained in monolayer cultures in Falcon tissue culture flasks using RPMI (Roswell Park Memorial Institute) 1640 containing fetal calf serum $5^{\circ}{ }_{11}, 1-\mathrm{M}$ Hepes $2 \cdot 3^{\circ} "$, penicillin $200 \mathrm{U} / \mathrm{ml}$, and streptomycin 100 $\mathrm{mg} / \mathrm{l}$.

Cells for use in the microcytotoxicity assay were collected mechically, washed, suspended in RPMI 1640 containing $5^{\circ}{ }_{0}$ fetal calf serum, and seeded into microtest plates to give a final concentration of about 100 cells per 10-il well. After incubation at $37 \mathrm{C}$ to allow for cell adhesion the culture medium was replaced by the test lymphocyte suspensions and adjusted to give a final lymphocyte target cell ratio of 400:1. After a further 48 hours' incubation cultures were inverted for two hours and then gently rinsed to remove detached target cells and lymphocytes. The cells remaining in the test and control wells were then counted with a graticule eyepiece at $\times 60$ magnification and the cytotoxicity expressed as:

$$
\frac{\text { (mean of control wells }- \text { mean of test wells) } \times 100}{\text { mean of control wells }}
$$

Each test was performed with at least 10 replicate wells, and each plate, consisting of 60 wells, had its own set of at least 20 control wells. The upper limit of the normal range of cytotoxicity was taken as $35^{\circ}$, , which is two standard deviations above the mean value of $4^{\circ} \%$ found for lymphocytes obtained from 10 healthy laboratory workers.

The same assay was used for the cytotoxicity studies with rabbit hepatocytes as target cells. The preparation of these cells has also been described in detail elsewhere, except that deoxyribonuclease was not incorporated in the enzyme mixture."

\section{PREPARATION OF ANTIGENS AND AGGREGATED IGG}

Tamm-Horsfall glycoprotein was prepared from normal human urine by precipitation with $\mathrm{NaCl}$ at $0.58-\mathrm{M}$ concentration. ${ }^{9}$ Liverspecific lipoprotein and a macromolecular kidney protein fraction (which did not contain Tamm-Horsfall glycoprotein), prepared from human liver and kidney obtained within a few hours of death, ${ }^{10}$ were also used in blocking experiments.

Aggregated immunoglobulin was prepared from normal human serum by a precipitation method using Rivanol ${ }^{11}$ and aggregated by heating at $63 \mathrm{C}$ for 15 minutes. ${ }^{1: 2}$

\section{Results}

Significant lymphocyte-mediated cytotoxicity for the baby hamster kidney cells was found in 10 of the 13 patients with renal tubular acidosis (fig 1). In contrast, cytotoxicity values fell within the normal range in 10 of the 12 patients in whom the acidification defect could not be detected, the difference from the findings in those with renal tubular acidosis being statistically significant $\left(y^{2}=6.2 ; \mathrm{P}<0.01\right)$. To study further the mechanism of the reaction, the assay was also performed after the addition of $5 \mu \mathrm{g}$ of aggregated IgG (fig 2). The mean cytotoxicity was reduced significantly from $66^{\%}$ to $14^{\circ}{ }_{0}$ (paired $t 7 \cdot 20 ; \mathrm{P}<0 \cdot 005)$.

A similar relationship could not be found between cytotoxicity for rabbit hepatocytes and a defect in urinary acidification. Of the 13 patients with renal tubular acidosis 10 showed lymphocyte-mediated cytotoxicity for hepatocytes, but this was also present in six of the 12 patients with a normal response to the acid load. Further evidence of the specificity of the cytotoxic reactions came from the results of the blocking experiments with three different antigens (fig 2). Thus in five patients with chronic active hepatitis and renal tubular acidosis cytotoxicity for kidney cells was reduced from a mean of $66^{\circ}$, to $12^{\circ} \mathrm{o}$ after the addition of $0.2 \mathrm{~kg}$ of Tamm-Horsfall glycoprotein (paired $t$ $8.88 ; \mathrm{P}<0.001)$ but was unchanged by the addition of $0.5: \mathrm{g}$ of liverspecific lipoprotein or kidney protein. In contrast, cytotoxicity for

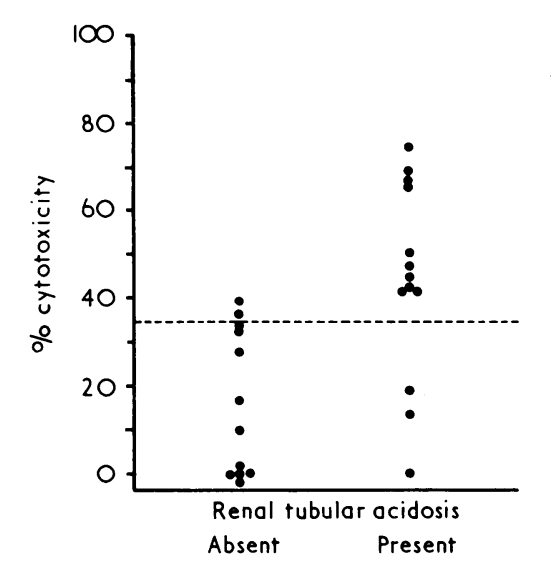

FIG 1-Lymphocyte cytotoxicity for baby hamster kidney cells in patients with autoimmune liver disease with and without renal tubular acidosis. Horizontal dotted line indicates upper limit of normal.

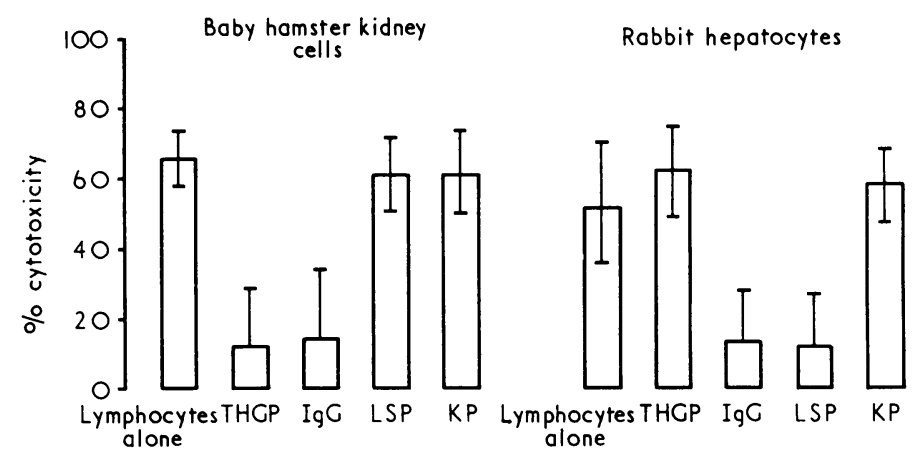

FIG 2-Mean lymphocyte cytotoxicity ( \pm 1 SD) for baby hamster kidney cells and rabbit hepatocytes (five patients) using lymphocytes alone and after the addition of either $0.2 \mu \mathrm{g}$ Tamm-Horsfall glycoprotein (THGP), $5 \mu \mathrm{g}$ aggregated IgG, $0.5 \mu \mathrm{g}$ liver-specific protein (LSP), or $0.5 \mu \mathrm{g}$ kidney protein (KP) added at the same time as the lymphocytes.

rabbit hepatocytes was not affected by Tamm-Horsfall glycoprotein or kidney protein but was significantly reduced from $53^{\circ}$, to $12^{\circ}$ o after the addition of liver-specific membrane lipoprotein (paired $t \quad 15 \cdot 40$; $\mathrm{P}<0.0001)$.

\section{Discussion}

This study clearly shows that lymphocytes from most patients with chronic active hepatitis or primary biliary cirrhosis complicated by renal tubular acidosis are cytotoxic for cells known to secrete Tamm-Horsfall glycoprotein, whereas this is a much less common finding in those with a normal response to an acid load. This suggests that lymphocytes sensitised to the glycoprotein can indeed damage renal tubular cells and thus be responsible for the acidification defect. The cellular interactions involved in the cytotoxicity reaction have yet to be analysed in detail, but we have recently shown that cytotoxicity for hepatocytes in patients with chronic active hepatitis is not mediated by $\mathrm{T}$ cells and may be blocked by aggregated immunoglobulin, suggesting an antibody-dependent, K-cell reaction. ${ }^{12}$ The results of adding aggregated IgG in the present study indicate that a similar mechanism is likely to be involved in the cytotoxicity for kidney cells with antibody to Tamm-Horsfall glycoprotein providing the link between $\mathrm{K}$ cells and the kidney cell line.

The question then arises as to why antibody to a renal tubular antigen should be produced in patients with a primary liver disease. Using an indirect immunofluorescence technique Tsantoulos et $a l^{3}$ showed antigenic material reacting with antibody to Tamm-Horsfall glycoprotein in the liver cell membranes of sections of human liver. Release of this material after damage to hepatocytes might initiate an immune response which, because 
of cross reaction between Tamm-Horsfall glycoprotein in the renal tubular cells and in hepatocytes, is directed at both the kidney and liver antigens. Direct cross reaction with the liverspecific membrane lipoprotein, however, was thought to be unlikely as there was no reaction on immunodiffusion between this antigen and an antibody to Tamm-Horsfall glycoprotein. This has been confirmed by the present blocking experiments, since Tamm-Horsfall glycoprotein blocked only the reaction against kidney cells, while the liver-specific protein effectively reduced cytotoxicity only for liver cells.

The proposed mechanism for initiating sensitisation to Tamm-Horsfall glycoprotein is more easily visualised in patients with untreated chronic active hepatitis, in whom hepatocellular damage is a prominent histological feature and lymphocytemediated cytotoxicity for hepatocytes is a constant finding, ${ }^{6}$ than in those with primary biliary cirrhosis, in whom, at least in the early stages of the disease, the inflammatory reaction is confined to the bile ducts. As the disease progresses, however, the cellular inflammation tends to spread into the lobule and with this there may also be piecemeal necrosis of periportal hepatocytes. Sensitisation to hepatocyte membrane antigens might then occur, and it is in these cases that renal tubular acidosis may be expected to arise.

Whether the many other systemic manifestations, including Sjögrens syndrome, found in chronic active hepatitis and primary biliary cirrhosis are also induced secondary to the liver disease by cross-reacting antigens, or whether they are due to other mechanisms such as deposition of circulating immune complexes or a common genetic predisposition awaits further investigation.

We are indebted to Dr R D Marshall (St Mary's Hospital) for kindly supplying cultures of baby hamster kidney cells and to the Wellcome Trust for their continuing support.

\section{References}

1, Golding, P L, Smith, M G M, and Williams, R, American fournal of Medicine, 1973, 55, 772 .

2 Smith, M G M, et al, British Medical fournal, 1972, 1, 527.

3 Tsantoulos, D C, et al, British Medical fournal, 1974, 4, 491.

4 Rhodin, J, in Renal Disease, ed D A K Black, 2nd edn, p 58. Oxford, Blackwell, 1967.

${ }^{5}$ Dunstan, D R, et al, Proceedings of the Royal Society, London, series B, $1974,186,297$.

6 Thomson, A D, et al, Nature New Biology, 1974, 252, 721.

${ }^{7}$ Rocklin, R, Mayas, O, and David, J, Fournal of Immunology, 1970, 104, 95.

8 Boyum, A, Scandinavian fournal of Clinical and Laboratory Investigation, 1968, 21, suppl 97, p 9.

${ }^{9}$ Fletcher, A P, Neuberger, A, and Ratcliffe, W A, Biochemical fournal, $1970,120,417$.

10 Eddleston, A L W F, et al, British Medical fournal, 1973, 4, 274

11 Heide, K, and Schwick, H G, in Handbook of Experimental Immunology, vol I: Immunochemistry, 6.1, ed D M Weir. Oxford, Blackwell, 1973. 12 Cochrane, A M G, et al, Lancet, 1976, 1, 441.

\title{
Neuropathy in experimental diabetes: an animal model
}

\author{
J JAKOBSEN，K LUNDBÆK
}

British Medical fournal, 1976, 2, 278-279

\begin{abstract}
Summary
A morphometric study of the common peroneal nerve in early experimental diabetes in rats showed that fibre size was diminished. The reduction in the size of the axon was twice that of the myelin sheath. This may contribute to the understanding of the impaired motor conduction velocity found in diabetics shortly after the onset of their disease.
\end{abstract}

\section{Introduction}

After many years of diabetes a few patients will develop signs and symptoms of disabling diabetic neuropathy. Most diabetics, however, can be shown to have asymptomatic neurological abnormalities soon after the clinical onset of their disease. These may be evaluated precisely from the motor conduction velocity. ${ }^{1}$ There is little information on the morphological basis of this early neurological disorder, partly because of the technical and ethical problems of performing nerve biopsies on patients without clinical signs of nervous disease. Attempts to construct an animal model of diabetic neuropathy to help explain diabetic nervous system disease have presented difficulties. In experimental diabetes-whether induced by alloxan, streptozotocin, or pancreatectomy - the same reduction of motor conduc-

University Institute of Pathology and Second University Clinic of Internal Medicine, Kommuehospitalet, 8000 Aarhus C, Denmark

J JAKOBSEN, MD, research fellow

K LUNDBÆK, MD, professor of medicine tion velocity is found as in diabetic patients. ${ }^{2-5}$ Morphological studies, however, have failed to show changes that could explain or be correlated with this conduction abnormality. ${ }^{4}$

We present the results of morphometric studies of peripheral nerves in early streptozotocin-induced diabetes in rats. A diminution in the size of the nerve fibres, especially the axons, was found, which may explain the impairment of nerve conduction.

\section{Methods}

For precise determination of nerve fibre size two points are important. Firstly, in cross-sections of peripheral nerves the fibres do not always appear as circles or ellipses but may take many other forms (fig 1). Use of a point-counting technique is therefore less likely to result in error than measurement of diameters. Secondly, because the size of nerve fibres increases with age, ${ }^{4}$ diabetic and control animals must be of the same age.

In the present study, diabetes was induced with streptozotocin in 10 male rats. During the experiment blood glucose values ranged from 16.7 to $33.3 \mathrm{mmol} / 1$ (300-600 mg/100 ml). After four weeks the two common peroneal nerves were fixed by vascular perfusion. Nerves from 10 control male rats-matched with the diabetic animals for age and weight-were treated likewise. The osmolality of the fixatives was maintained within a narrow range. Transverse semi-thin sections were cut from plastic-embedded tissue by placing the nerve perpendicular to the edge of the glass knife of the LKB Ultrotome with the aid of a 10-times-magnifying ocular fitted with cross-hairs. The identity of the specimens was unknown both to the technician making the sections and to JJ, who performed the measurements.

Representative samples of the fibre population of one of the common peroneal nerves from each animal were taken by random selection of circle sectors including an average of 250 fibres. Within the sectors the number of test points of a simple square lattice of 10 points/ 